\title{
MIGUEL VERDIGUIER Y EL RETABLO DE LA CAPILLA DEL HOSPITAL DE JESÚS NAZARENO DE LUQUE, CÓRDOBA. NOTAS PARA SU HISTORIA
}

\author{
JUAN LUQUE CARRILLO \\ Cabildo Catedral de Córdoba
}

\begin{abstract}
Resumen
De la abundante nómina de artistas extranjeros activos en España entre mediados del siglo XVIII y las primeras décadas del XIX, sobresale, en el marco de la Andalucía Occidental, la figura del francés Miguel Verdiguier (1706-1796), escultor, gran maestro barroco de orientación italiana que fundó en 1753 la Academia de Pintura y Escultura de Marsella. Años después aparece afincado en Córdoba, trabajando para su cabildo catedralicio y obras del Obispado, con encargos en algunas localidades de la Diócesis, caso de Luque, para cuya capilla del Hospital de Jesús Nazareno diseñó en 1776 el retablo que preside su altar mayor. La documentación consultada en el actual archivo patronal del Hospital confirma la autoría del maestro y otros datos referentes a su fábrica.
\end{abstract}

\section{Palabras clave}

Hospital de Jesús Nazareno, Luque, Miguel Verdiguier, siglo XVIII, Neoclasicismo.

\section{MIGUEL VERDIGUIER AND JESUS NAZARENE OF LUQUE'S HOSPITAL CHAPEL ALTARPIECE, CÓRDOBA. COMMENTS FOR ITS HISTORY}

Abstract

From the abundant list of active foreigners artists in Spain between mid eighteen century and the first decades of nineteen century excels, in the field of Western Andalusia, the French Miguel Verdiguier (1706-1796), sculptor, great master of the baroque of Italian orientation who founded in 1753 the Painting \& Sculpture Academy of Marseilles. Years later he appears in Cordova, working for his cathedral chapter and works of the bishopric, with orders in some localities of the province, Luque case, for whose church of the Jesus Nazareno's Hospital designed in 1776 the altarpiece that presides over its main altar. The documentation consulted in the Hospital's patronal archive confirms the authorship and other pieces of date in reference to his work

\section{Keywords}

Jesus Nazarene's Hospital, Luque, Miguel Verdiguier, 18th Century, Neoclassicism. 


\section{La Villa de Luque en el siglo XVIII: fundación del Hospital de Jesús Nazareno}

Frente a la proyección del movimiento antihospitalario de la España de mediados del setecientos y sus drásticas consecuencias en el marco de las instituciones benéficas de origen medieval, un nuevo capítulo para la historia social de la villa de Luque, en Córdoba, daría comienzo en 1752 gracias a la iniciativa de la fundación del Hospital de Jesús Nazareno, en uno de los barrios fronterizos al primitivo casco urbano de la localidad. Al igual que otros muchos ejemplos andaluces de los siglos XVI y XVII, se trató de una institución local de carácter estrictamente asistencial, fundada por don Cristóbal José Roldán Baena (1687-1752), clérigo, natural y vecino de Luque, hijo de Cristóbal Rafael Roldán y de Juana León, cuyos apellidos lo entroncan con las familias más elitistas de la hidalguía local del momento, escasa pero de gran proyección en el conjunto de la aristocracia cordobesa, donde aún pervivía con fuerza la división estamental y el sentido providencialista heredado de la mentalidad del Medievo'.

Fallecido el 24 de enero de 1752, don Cristóbal José fue sepultado en la capilla de Nuestra Señora del Carmen de la parroquia de la Asunción de Luque, de la que era capellán y administrador de su fábrica. Una lápida de mármol en dicha capilla, destruida durante las obras de la década de 1960 en el templo, informaba con detalle sobre la personalidad de este clérigo. La iniciativa de fundar el referido hospital quedó manifestada precisamente en una de las clausulas de su testamento, donde dejó expresado "a mucho tiempo tengo gran deseo y voluntad para mayor servicio de Dios nuestro Señor y beneficio particular de mis parientes y del comun desta villa, de fundar en ella un hospital donde se curen continuamente seys pobres enfermos [...]"2. El documento fue redactado en Luque el 19 de enero de 1752, ante la fe del notario Juan Serrano y Roldán, y en él se hace referencia a una serie de fincas rústicas y urbanas legadas para levantar el inmueble y de cuyas rentas se mantendría. Las principales clausulas del testamento, junto a otros documentos fundacionales de carácter institucional, fueron dadas a conocer en 1988 por V. Estrada Carrillo en su estudio monográfico sobre el edificio, donde compiló la historia clínica, social y religiosa de la fundación, en base a la información documental custodiada en los fondos patronales ${ }^{3}$. Una copia testimoniada del documento, expedida el 20 de diciembre de 1771 y conservada en el archivo del actual patronato del Hospital, informa con precisión de los deseos del testador para después de su muerte.

Estimando insuficiente el legado de bienes fundacional, don Cristóbal José otorgó asimismo un codicilo dos días después del testamento, acreciéndolo, pero sin ninguna norma estatutaria más. Aparecían como condiciones de fundación que la fábrica del hospital contara con "una enfermeria alta y baxa y oratorio y oficinas correspondientes [...]" . Igualmente, por voluntad de la hermana del fundador, María Josefa Roldán, heredera y cofundadora de la institución, se dispuso en el testamento que cuando estuviera finalizado el hospital, las camas deberían estar acondicionadas con "dos colchones, cuatro sabanas y un paño para cada una $[\ldots]$ ". En líneas generales, estas clausulas fundacionales responden al criterio propio de la época: instituciones comarcales, caso de las fundadas en las vecinas localidades de Baena o Castro del Río, expresadas en términos similares, mostrando especial preferencia por los vecinos de la villa, condición ésta muy poco tenida en cuenta o, en todo caso, sin el rigor con que se expresa.

\footnotetext{
1 Sobre este tema véase: Jiménez, 1958.

${ }_{2}^{2}$ Copia del testamento de don Cristóbal José Roldán Baena, 19 de enero de 1752, Archivo Patronal del Hospital Jesús Nazareno de Luque, Córdoba (APHJNL), Legajo 1, s/f.

3 Estrada, 1988.

${ }_{4}$ Copia del testamento de don Cristóbal José Roldán Baena, 19 de enero de 1752, APHJNL, legajo 1, s/f.

5 Ídem.
} 


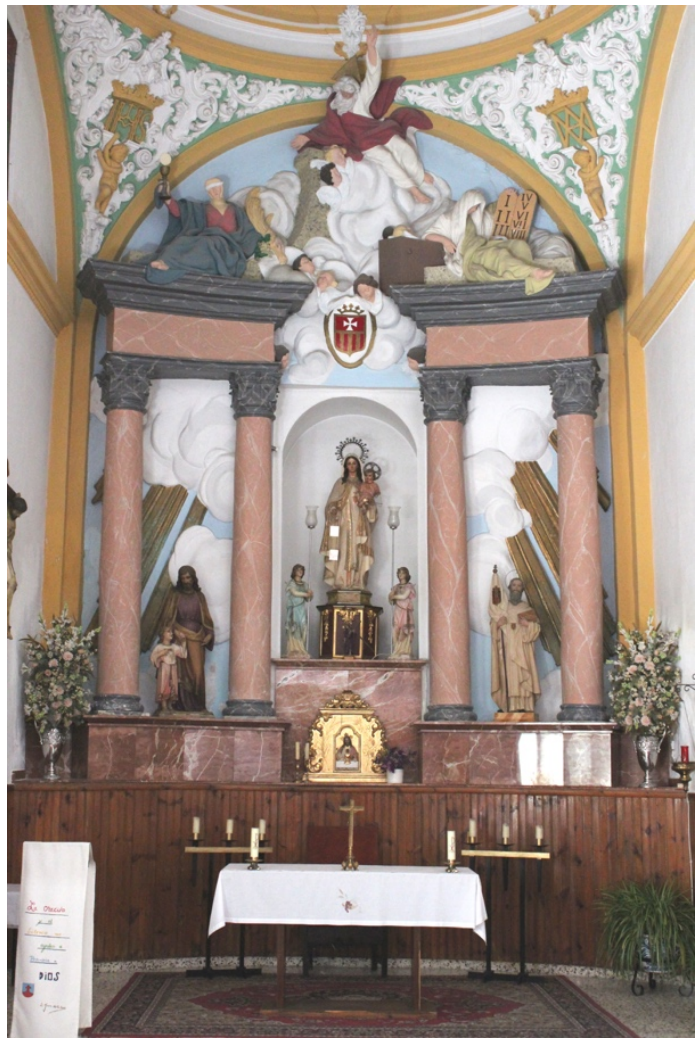

Fig. 1. Retablo de la capilla del Hospital de Jesús Nazareno, Luque, Córdoba. Miguel Verdiguier. 1776. Fotografía del autor

En las clausulas nombra el testador por patronos a los poseedores del vínculo; pues, con la creación de éste, relaciona los que sucesivamente habrían de poseerlo y nombra por primera titular y heredera universal a su hermana María Josefa, viuda de Francisco Rosillo de Vedmar, matrimonio del que no se ha documentado descendencia directa. Así las cosas, a la muerte de ésta, le sucedió su sobrina Josefa Cristina, hija de Isabel, otra hermana, y sucesivamente los demás hijos de ésta y sus descendientes, según la norma de los mayorazgos: preferencia del mayor al menor, y del hombre a la mujer ${ }^{6}$.

De igual modo resulta de gran interés el testamento de María Josefa. En él, la señora se muestra fiel y solidaria a la voluntad de su difunto hermano, en cuanto a la construcción del hospital. Dificultades burocráticas y económicas hicieron que, cuatro años después de la muerte de don Cristóbal José, y cercana la suya, la obra se hallara solo comenzada. Ello es motivo de gran preocupación para la patrona, que ve próxima su muerte y el mandato incumplido. Probablemente la envergadura de la obra desbordaba su capacidad de disposición y organizativa y le hacía difícil el cumplimiento contraído. Así, con el fin de acelerar el proceso constructivo, y ante la realidad del fin de sus días, María Josefa optó por responsabilizar a su sobrino Antonio de Vida y Baena, presbítero y administrador del Hospital, nombrándolo heredero de la fundación con la condición de que debía terminar la obra en el plazo máximo de dos años. No obstante, ni Antonio de Vida, ni durante los dos años expresados, se terminó la obra del inmueble ; es más, fallecida María Josefa el 29 de abril de 1756, habría de esperar 16 años más para asistir a su inauguración. Queda, pues, bien expresada la voluntad de María Josefa frente al proyecto fundacional de su hermano, al reunir numerosos bienes con los que dotó solidariamente a la obra, aunque con una especial ineficacia en lo referente al proceso constructivo. Ni el mandato moral, ni el material de ser herederos, fueron suficientes para sacar adelante la obra con la rapidez que se quería.

\footnotetext{
6 Ídem.

7 Testamento de doña Maria Josefa Roldán Baena, APHJNL, legajo 1, s/f.
} 
Finalmente en 1761, noticioso el Obispo don Martín de Barcia (1756-1771) ${ }^{8}$ de toda la trayectoria de la fundación, comisionó al hermano Antonio de Jesús para que alentara y emprendiera la apertura definitiva del Hospital. Este religioso de origen portugués pertenecía a la Congregación Hospitalaria de Jesús Nazareno y, desde 1741, ocupaba además el cargo de presidente de otro hospicio similar en Castro del Río. A su muerte, le sucedió el Hermano Matías de San José, del que se conocen muy pocos datos biográficos. Fuera por falta de vocaciones, o bien por un exceso de casas y enfermos a los que atender, la comunidad no se renovaba; los cinco hermanos, más el presidente, permanecieron fijos, y sus fallecimientos no se cubrieron?'

Esta asistencia se fue haciendo cada vez más precaria con el inicio del siglo XIX y los comienzos del Liberalismo en Cádiz. Las medidas y nuevas disposiciones del gobierno liberal provocaron, entre otros avatares, el abandono del hábito por parte de más de una tercera parte de los religiosos. Los hermanos de Jesús Nazareno se vieron directamente muy afectados, hasta el punto de que a mediados del siglo XIX, ya no tenían noviciado, encontrándose la orden prácticamente extinguida. En el caso de Luque, en 1823 se registra la última relación de cuentas, presentada por el Hermano Venancio de la Concepción ${ }^{10}$, iniciándose poco tiempo después el relevo en el gobierno de la fundación conforme a los nuevos dictámenes de la Administración.

La Desamortización de 1855 hizo que el patrimonio de la fundación se pusiera en venta mediante subasta pública, salvo el edificio, produciéndose una reactivación importante en la vida del conjunto, reflejada en el considerable aumento de asistidos. No obstante la situación debió mantenerse poco tiempo, pues un acuerdo del Cabildo de 1880 propuso abrir nuevamente las puertas del Hospital por encontrarse cerrado desde hacía tiempo, como consecuencia de la falta de medios. Con mucho esfuerzo se consiguió reabrirlo y ponerlo en actividad, siendo éste el momento en que se instalaron las Hermanas Mercedarias de la Caridad, sin cuya presencia probablemente no hubiera sido posible dicha apertura.

De la estancia de la comunidad religiosa en el Hospital a lo largo de casi un siglo no ha quedado documentación alguna que testimonie su presencia. No obstante, durante la administración de las mercedarias, el Hospital perdió la finalidad social de beneficencia y en sustitución, se instalaron dos escuelas; una mixta para párvulos y otra de niñas mayores que, para más significación, era de pago. No solo las reglas de la Beneficencia, sino las propias de la Congregación, quedaban así de entredicho.

Finalmente, en la década de 1960 desaparecieron las escuelas y se hicieron obras de adaptación y acondicionamiento para un asilo de ancianos. Alrededor de una treintena de personas mayores fueron asistidas durante algunos años. El limitado número de personal de trabajo, la escasez de subvenciones por parte de la Administración y la falta de condiciones físicas del inmueble para este menester, determinaron el levantamiento de la institución y con él, la presencia de la comunidad religiosa de nuevo. Tras la marcha definitiva de las religiosas en 1980, se abrió nuevamente el Hospital, esta vez con una doble funcionalidad: asilo y cooperativa de confección textil. No obstante ambos proyectos fracasaron a finales de la centuria pasada. El inicio del siglo XXI trajo consigo el cambio de patrono de la institución, comenzando una nueva andadura para su futuro en la que destacó, como nota característica, la estabilidad del conjunto. Desprovisto completamente del espíritu asistencial con el que fue creado en el último tercio del siglo XVIII, el Hospital de Jesús Nazareno de Luque, con don Carlos Orense a la cabeza como actual patrono, es sede de la fundación y centro social donde se imparten cursos y seminarios dirigidos especialmente a los vecinos del pueblo, centrados en actividades agrícolas y del sector primario del que se sostiene la economía local.

\footnotetext{
${ }^{8}$ Gómez, 1778: 812.

9 Estrada, 1988: 30.

10 Cuaderno de cuentas de fábrica de 1823, APHJNL, doc. 5, s/f.
} 


\section{La década de 1760: Miguel Verdiguier y su llegada a la provincia de Córdoba}

Miguel Verdiguier fue uno de los numerosos artistas franceses que, junto a otros muchos de origen italiano, se instalaron en España a lo largo del siglo XVIII, contribuyendo a la difusión de las nuevas corrientes artísticas italianas y del tradicional clasicismo francés anterior a la Revolución ${ }^{11}$. Su región natal -la Provenza-, estuvo siempre muy próxima a la Italia del norte, tanto geográfica, como cultural y artísticamente, lo que hizo posible una rápida y fácil asimilación de la corriente barroca berninesca por parte del escultor francés. No obstante su evolución corrió más bien paralela al movimiento academicista, base del Neoclasicismo que posteriormente se propagaría por toda Europa.

Tradicionalmente se le ha considerado uno de los principales artistas foráneos que desvirtuaron la tradicional línea barroca que, al finalizar el siglo, quedaría transformada en aquel Neoclasicismo impuesto por la Real Academia de San Fernando. El hecho de ser fundador y director de la Academia de Pintura y Escultura de Marsella, hizo que su personalidad artística adquiriera una gran dimensión académica, al tiempo que su preparación profesional en la Provenza y sus estancias en Italia, hicieron de él un buen conocedor del barroco romano, cuyos planteamientos eran enseñados en los principales núcleos y centros artísticos del momento ${ }^{12}$. Esta simbiosis artística entre ambos estilos dio pie en 1992 al profesor D. Sánchez-Mesa a acuñar la expresión "barroco atemperado", para referirse a ese momento transitorio en el que toda una generación de artistas participó de los últimos ecos barrocos dentro del espíritu academicista, entre ellos el propio Verdiguier y otros importantes maestros de procedencia fundamentalmente centroeuropea ${ }^{13}$. Aunque sus primeras obras francesas fueron de carácter civil, finalmente trabajó con más frecuencia para la Iglesia; en el caso de España con un estilo maduro y experimentado donde desarrolló lo mejor de su arte a lo largo de sus más de treinta años de incesante trayectoria, recurriendo a partir de la década de 1770 al empleo del estuco como material fundamental, en sustitución de la madera, característica ésta que marcó el resto de su trayectoria profesional, como puede observarse en obras realizadas en algunos pueblos de la provincia, caso de La Rambla, Puente Genil o el ejemplo del que nos ocupamos, Luque.

Gracias a su amigo y compatriota Baltasar Dreveton (act. en la segunda mitad del siglo XVIII), Verdiguier llegó en el año 1763 a la Diócesis de Córdoba para trabajar en la decoración de la Capilla de Santa Inés de la Catedral, y terminar la obra del Triunfo de San Rafael junto a la Puerta del Puente, proyecto antiguo que se encontraba paralizado desde hacía tiempo, y que el obispo don Martin de Barcia pretendía poner en marcha con la mayor brevedad posible ${ }^{14}$. En su primera carta a la Academia marsellesa desde España, Verdiguier habla de su llegada a la Península un 28 de junio, víspera de la festividad de los santos Pedro y Pablo, y en ella destaca su cálido recibimiento y relación con el obispo de la Diócesis, con el que se comunicaba directamente en italiano, idioma conocido por ambos debido a sus anteriores estancias en Roma.

En esta primera carta, el escultor reflejó también sus impresiones personales sobre Córdoba, a modo comparativo con los conocimientos que le habían llegado anteriormente a través de Dreveton, lo que demuestra que había tenido contactos frecuentes antes de su llegada a la ciudad. Sin embrago, no tardó en aparecer grandes discrepancias y disgustos personales entre ambos artistas, causadas por enfrentamientos y rivalidades profesionales, de manera que aquella amistosa colaboración entre los dos franceses, rápidamente quedó

11 En 2007 Antonio Gómez-Guillamón Maraver defendió en la universidad de Málaga la tesis titulada Vida y obra de Juan Miguel Verdiguier. Escultor Franco-Español del siglo XVIII, dirigida por la prof. Catedrática Rosario Camacho Martínez. Los resultados de esta tesis doctoral supusieron un gran avance para el estudio de la vida y producción del artista francés.

12 Buesa/Oruezabal, 2003: 988-1006.

13 Sánchez-Mesa, 1992: 269-296.

14 Nieto, 1998: 560. 
Fig. 2. Retablo de la capilla del Sagrario, Parroquia de la Asunción, La Rambla, Córdoba. Miguel Verdiguier. 1775. Fotografía del autor.

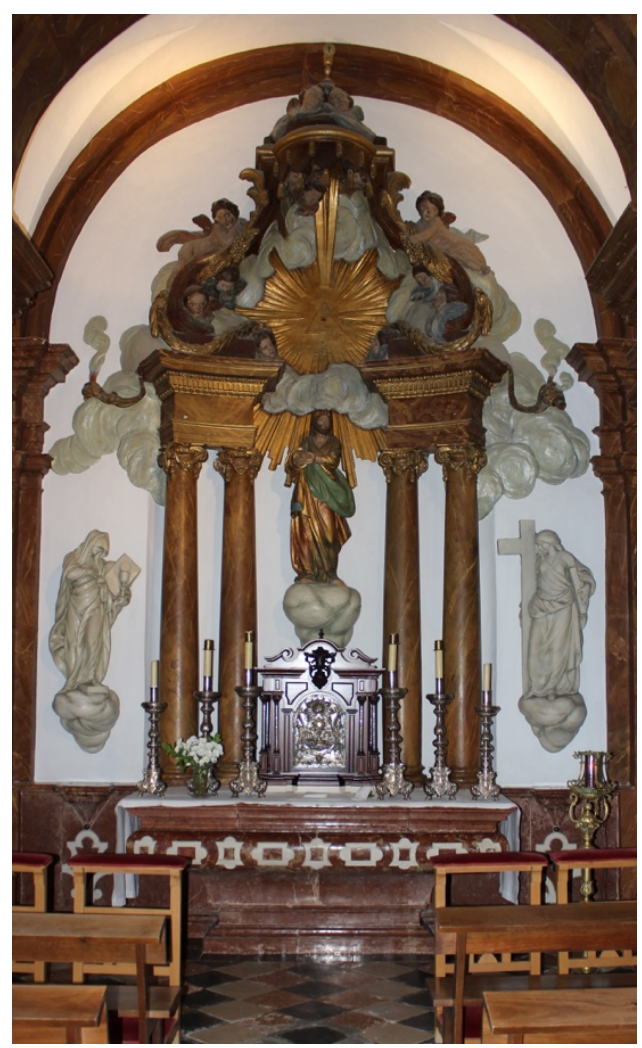

truncada en una odiosa competencia que llegó a romper su mutuo respeto y admiración personal $^{15}$.

Paralelamente Verdiguier pretendió fundar en la ciudad una academia a imagen y semejanza de la marsellesa, centrando buena parte de sus esfuerzos y tiempo libre en el proyecto, aunque finalmente la idea no maduró y todo quedó en un simple intento. Así se deduce de una de sus cartas enviadas en 1764 al pintor francés Gabriel Moulinneuf, en cuya contestación, éste le recriminó su falta de atención a la Academia de Marsella al encontrarse absorbido en la fundación de la cordobesa ${ }^{16}$.

Años después, en 1780, su nombramiento como Académico de Mérito en la Real Academia de Bellas Artes de San Fernando, le abrió las puertas de la ciudad de Granada que, tras Córdoba y Sevilla, se convirtió en su último lugar de trabajo. Allí se mostró ante todo como el gran maestro que supo renovar el barroco andaluz del momento, rompiendo la frialdad del nuevo Neoclasicismo que, poco a poco y durante el reinado de Carlos III, fue imponiéndose. Con todo, la década de 1770 fue el momento del mayor auge profesional del artista, debiéndose a estos años la mayoría de sus más destacados trabajos repartidos por Córdoba capital y pueblos del sur de la provincia, donde el escultor demostró una gran experiencia en el diseño de retablos y exquisitez a la hora de sus decoraciones, respondiendo siempre a los nuevos conceptos promulgados por el movimiento academicista.

\section{Un retablo para el Hospital de Jesús Nazareno de Luque. Evolución histórica y análisis artístico}

Desde su llegada a la ciudad de Córdoba, afectado por una debilidad emocional manifestada en insomnios y frecuentes dolores de cabeza, demostrada en los estudios

15 Gómez-Guillamón, 2010: 145.

16 Ídem. 


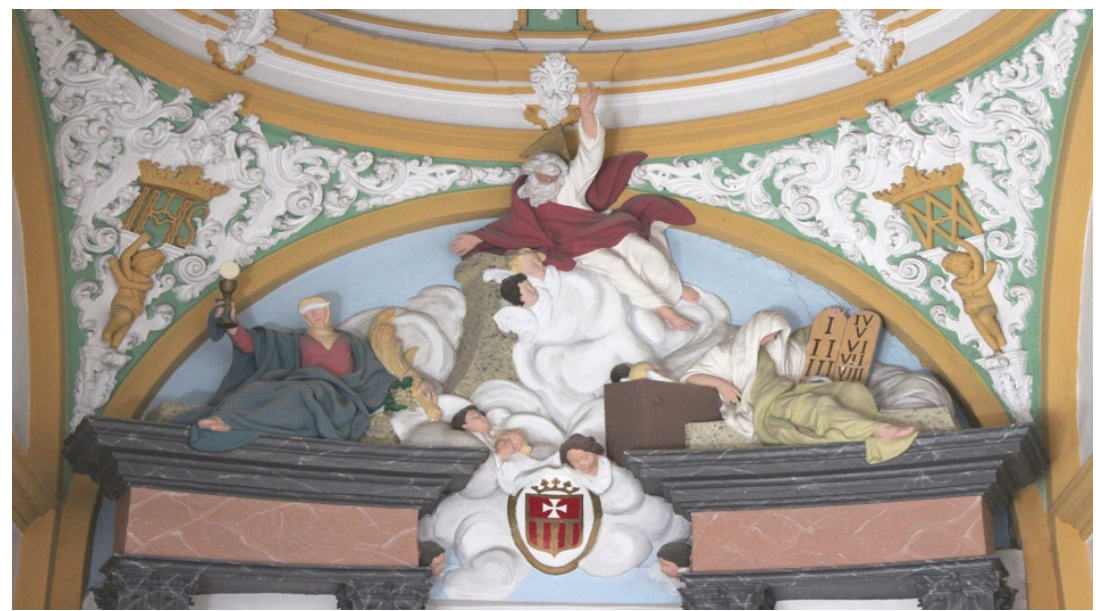

Fig. 3. Por menor del Nazareno, ático, Retablo de la capilla del Hospital de Jesús. Fotografía del autor.

grafológicos de sus cartas, Miguel Verdiguier intentó cubrir las necesidades artísticas demandadas por la jerarquía eclesiástica y élite social cordobesa del momento, incorporando las novedades estilísticas del último tercio del setecientos y apostando por el nuevo lenguaje artístico de mayor proyección academicista.

En esta decidida línea de evolución artística, Verdiguier viajó al sur de la provincia a mediados de la década de 1770 para contratar una de sus obras más singulares y sin duda mejor documentadas: el retablo que preside el presbiterio de la capilla hospitalaria de Jesús Nazareno de Luque, encargo en el que el artista trabajó durante toda la primera mitad del año 1776 por el precio de 10.000 maravedíes. Esta obra debió llevarla a cabo justamente después de concluir sus trabajos en el retablo de la Capilla Sacramental de la Parroquia de la Asunción de La Rambla, terminado en febrero de 1775, como informa la documentación enviada meses después por el mayordomo de la Cofradía del Santísimo Sacramento, al obispo don Francisco Garrido de la Vega (1772-1776) ${ }^{17}$, donde el religioso describe la intervención del escultor del siguiente modo: "además de haber gastado en su manutencion doscientos rreales le comunica la finalizacion de las obras [de la Capilla del Sagrario de La Rambla] realizadas por Verdiguier el dia 30 o 31 deste presente mes [...] para no detener a D. Miguel $[\ldots]$ porque tiene que empezar una obra semejante en el sagrario del Hospital de Jesus en la villa de Luque $[. . .]^{, 18}$.

Coincidiendo con la fecha de entrega de la obra, en julio de 1776 quedó registrada la entrega al escultor de los 10.000 maravedíes en que se concertó la obra, firmando dicha entrega y su correspondiente carta de pago con la que se concluyó el proyecto. Así consta en el cuaderno de cuenta y razón del dinero recaudado por las limosnas, donde aparece un asiento de dicho año con el siguiente concepto: "Mas es datta desta quenta diez mil maravedis que se dieron a Don Miguel Verdiguier por el retablo que hizo para el altar maior los ocho mill se sacaron del arca de deposito y los dos de los productos de las rentas de que ai recibo $[\ldots]^{\prime \prime 19}$. También se anota la siguiente información referente a los oficiales que trabajaron en la obra: "es datta desta quenta seiscientos ochenta rreales que se tomaron de Jose Matencio y Rafael Moreno veçinos de la ciudad de Cordova y son por la manutencion del tiempo que

17 Gómez, 1778: 823.

18 Informe de la Cofradia del Santísimo Sacramento a Mons. Francisco Garrido de la Vega, 25 de enero de 1775, Archivo General del Obispado, Córdoba, AGOC, legajo 18, carta 2, s/f.

19 Relación de las cuentas de la fundación del Hospital de Jesús Nazareno de Luque, año 1776. APHJNL, Legajo 1. Libro 1, s/f. 
estubieron travajando en el retablo de quenta de Don Miguel Verdiguier y davan a tres rreales por dia $[\ldots]^{, 20}$.

Esta capilla del Hospital de Jesús Nazareno, en cuya cripta descansan los restos de Fray Antonio de Jesús, responde al modelo de oratorio sencillo de una sola nave, cubierto con bóveda de cañón y cúpula en el presbiterio; un tipo de distribución espacial sencilla, aunque funcional, ya conocida en España desde hacía siglos, cuyo modelo fue también proyectado en el continente americano a partir de las primeras conquistas del siglo XVI, con especial significación en el Virreinato de Nueva España ${ }^{21}$. En la clave del arco toral de la Capilla, en un medallón decorado con motivos vegetales en yeso, reza la fecha de 1759, año en que se iniciaron los trabajos de albañilería.

Como en otras composiciones anteriores, Verdiguier aprovechó el ara del altar y sobre él erigió el banco, levantando a continuación el cuerpo principal del retablo, en estuco, material que introdujo por vez primera en el citado retablo de La Rambla y que, de igual modo, empleó años después para ejecutar el desaparecido retablo de la Capilla del Oratorio de San Felipe Neri, actual sede del gobierno y administración militar de Córdoba. Este material lo utilizó el artista mezclando cal apagada con polvo de mármol y cola que, siendo más barato que el mármol, seguía la normativa dictada por entonces en la Real Academia debido a su menor coste económico, obteniendo resultados de gran nobleza y sensaciones plásticas ${ }^{22}$ (figs. 1 y 2).

A diferencia del resto de escultores cordobeses del momento -desconocedores del uso del estuco-, Verdiguier ya había experimentado y conocido las propiedades de este material durante su primera etapa en Francia, país donde ya se había generalizado su uso ${ }^{23}$. Este era un material muy versátil y con características muy novedosas. Bien trabajado, ofrecía una gran calidad al tiempo que sorprendía por su economía en comparación con los trabajos pétreos, tratándose además de una solución muy práctica para la sustitución de la tradicional madera por otros materiales más novedosos, como sugería la nueva normativa oficial impuesta por la Academia ${ }^{24}$. De este modo, mediante diferentes tipos de cal ligados al polvo de mármoles, el artista conseguía una experiencia muy cercana al auténtico mármol.

De características muy similares al del Sagrario de La Rambla es este retablo de Luque: una composición de un solo cuerpo organizado en tres calles; la central y dos laterales, separadas por pares de columnas a los lados con basas, fustes lisos y capiteles compuestos que, en sentido cóncavo y soportando un arquitrabe partido, enmarcan una hornacina central de medio punto con la imagen de Nuestra Señora de las Mercedes. No obstante, en origen y según un inventario de 1780, este nicho estaba presidido por una imagen de Nuestro Padre Jesús Nazareno, titular del Hospital, talla de vestir que desde 1977, se encuentra cedida en depósito a la iglesia conventual de Madre de Dios de Lucena, Córdoba ${ }^{25}$. En los intercolumnios laterales aparecen hoy las imágenes de san José con el Niño, en el intercolumnio izquierdo, y san Pedro Nolasco en el derecho.

Uno de los elementos más singulares de la producción retablística de Verdiguier es el rompimiento de gloria, de gran influencia italiana, al modo de las creaciones seiscentistas de Bernini y sus principales discípulos romanos. Estos rompimientos de gloria suelen cerrar los áticos de los retablos mediante dinámicas y teatrales escenas presididas por la paloma del Espíritu Santo o, en su defecto, referencias a la Santísima Trinidad o representaciones figuradas de Dios Padre. No obstante, desde el punto de vista compositivo, son diseños que responden claramente a modelos clasicistas, acordes con su formación academicista. Concretamente, en el caso de Luque, el artista diseñó un rompimiento centrado por la imagen de Dios Padre representado en forma de anciano coronado con el triángulo alusivo a la

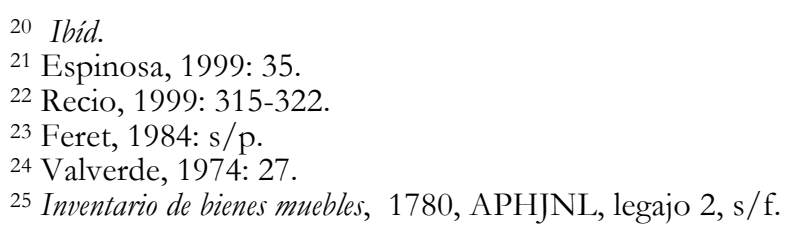






Fig. 4. Por menor Alegoría de la Antigua Ley Retablo de la capilla del Hospital de Jesús Nazareno. Fotografía del autor.

Santísima Trinidad y, a su alrededor, bellos y juguetones querubines que flotan entre nubes azuladas y rayos dorados, mientras se dirigen hacia la hornacina central, aportando dinamismo al sólido esquema de la composición (fig. 3). Recostada sobre el arquitrabe, en el lateral izquierdo, aparece una alegoría femenina con los ojos vendados y un copón en su mano derecha; es la personificación de la Fe, en alusión a la Nueva Ley, mientras que en el lado de la Epístola, a semejanza de la anterior, aparece otra alegoría femenina, en este caso con la cabeza cubierta por un manto y las Tablas de Moisés en su mano izquierda, aludiendo a la Torá, la Antigua Ley ${ }^{26}$ (fig. 4).

Al margen de su estudio iconográfico, la documentación consultada informa de un accidente ocurrido solo cinco años después de su terminación, causado por la incursión de un rayo en el interior de la capilla que provocó severos daños en la fábrica del retablo, iniciándose rápidamente los trámites y permisos para la reparación de la recién estrenada obra. Una factura con fecha del día 3 de julio de 1781, presentada por Diego González Mota, maestro dorador de Baena, informa con detalle de los jornales, herramientas y materiales empleados durante las obras preventivas e intervención específica. La factura finalmente ascendió a 536 reales y ofrece datos útiles para la recreación del suceso ${ }^{27}$. Imaginamos la magnitud del accidente tras la reconstrucción de una de las columnas de la calle lateral izquierda, el refuerzo de los basamentos y la consolidación de los elementos sustentados del rompimiento de gloria, con el fin de evitar una sobrecarga en las piezas sustentantes y su posible derribo, aparte de las labores de policromía, dorado y embellecimiento final.

Los cuadernos de cuentas de fábrica no registran nuevas restauraciones durante los siglos XIX y XX, a excepción de la problemática intervención de 1995 que desvirtuó la labra original de la imaginería conjunta, mediante la incorporación de los símbolos marianos del ático y el escudo de la Orden Carmelita que campea en el centro del arquitrabe, sobre la hornacina central, así como los relamidos contornos y colores brillantes de los personajes.

La imaginería de esta capilla del Hospital de Jesús Nazareno ha variado substancialmente de la original del siglo XVIII ya que, según un inventario del año 1780, existían las siguientes imágenes, conjuntamente con el retablo de estuco: una imagen de Jesús Nazareno "y por lo bajo, urnita con un Niño Jesus", y dos tallas de San Antonio ${ }^{28}$.

\footnotetext{
${ }^{26}$ Réau, 1999: 242.

27 Estrada, 1988: 61.

28 Inventario de bienes muebles, 1780, APHJNL, legajo 2, s/f.
} 
Dos inventarios fechados en 1880 muestran ahora un aumento notable de la imaginería de la Capilla, destacando al respecto una efigie de bulto redondo de Jesús Nazareno con camisa y diferentes túnicas, una dolorosa con la advocación del Mayor Dolor, también de bulto y con diferentes vestidos y velos, una imagen de San Juan Evangelista, una efigie de San Antonio de Padua con el Niño, otra de San José, otra de la Purísima Concepción, con corona de hoja de lata, un Niño con la advocación de Dulce Nombre de Jesús y, por último, otro Niño Jesús en una urna dorada ${ }^{29}$.

El estudio de estos inventarios permite sacar las siguientes conclusiones: en primer lugar, tanto en el de 1780, como en el de 1880, se hace mención a la imagen de Jesús Nazareno, por lo que ésta debió pertenecer al retablo original de Verdiguier. No obstante, en 1977 como ya se ha indicado-, la imagen fue cedida a la iglesia conventual de Madre de Dios, en Lucena, donde en la actualidad recibe culto y es venerado con profunda religiosidad ${ }^{30}$.

Las dos tallas de San Antonio recogidas en 1780, parecen responder más bien a un error de inventario, al documentarlas de forma repetida como "un San Antonio de talla [...] y otro Señor San Antonio con el mismo adorno" 31 ; sin embargo, en 1880 aparecen dos imágenes acompañadas del Niño, pero de diferentes santos: San Antonio de Padua y San José. Pensamos que en el primer inventario de 1780 pudo haber un error de identificación, siendo en realidad dos santos diferentes, y no dos San Antonios.

Al margen de la información de los inventarios y las conclusiones reseñadas, cabe la hipótesis de que la imagen de Jesús Nazareno sea quizás anterior al retablo de Verdiguier. Al respecto sugiere el profesor Villar Movellán la posible cronología y procedencia de la escultura, creyendo muy factible la década de 1720 y su vinculación con algún taller granadino representante de la tendencia rococó, extinguida -en el caso de Granada-, con la muerte en 1773 del maestro Torcuato Ruiz del Peral y la disolución de su taller ${ }^{32}$.

En líneas generales, se trata de un nazareno realizado en madera policromada, de tamaño ligeramente inferior al natural, dotado de un especial simbolismo y singular belleza reflejada en los rasgos faciales y equilibrio compositivo. El cuerpo de Cristo, encorvado por el peso de la cruz, presenta los rasgos fisionómicos propios de los nazarenos de principios del setecientos: rostro de semblante sereno, dulce mirada, nariz aguileña y boca entreabierta (fig. 5). Quizá el tipo de policromía mate y el modo de resolver la barba bífida, confirman la vinculación con la escuela granadina. Según el informe y presupuesto presentado por el escultor Santos Calero, cuando la imagen se trasladó de Luque a Lucena en 1977, acusaba un gran deterioro por su antigüedad y mala conservación, destacando en el documento que sus actuales manos no eran las originales, sino un añadido posterior con calidades muy inferiores al resto de la talla ${ }^{33}$.

Recuperada en 1977 por Antonio Rodríguez Delgado y Juan Miguel Calvillo García de la Parroquia de la Asunción de Luque, su estado era muy deficiente, hallándose almacenada en el desván de la iglesia a consecuencia del expolio llevado a cabo por la superiora de la comunidad que convirtió la capilla del Hospital en almacén. Tras ser intervenida en 1983 en el taller del citado escultor, en la actualidad procesiona con la advocación del Santísimo Cristo de la Pasión, conocido también popularmente como "Cristo del derribo". El permiso para su traslado a Lucena como depósito, una vez autorizado por el obispo don José María Cirarda (1971-1978), fue firmado por el cura párroco de la Asunción de Luque, don Manuel Cuenca, quien aún recuerda el episodio con especial desagrado.

Años antes del traslado del Nazareno, según un acta notarial de 16 de diciembre de 1972, Venancio Arias Riesco, vecino jubilado de Luque, donó para obras de reparación de la Capilla y servicios del Hospital 196.487 pesetas como muestra de agradecimiento y gratitud a los

\footnotetext{
29 Inventario de bienes muebles, 1880, APHJNL, legajo 3, s/f.

30 En ambos inventarios también se recoge una urna con el Niño, actualmente en paradero desconocido.

31 Inventario de bienes muebles, 1780, APHJNL, legajo 2, s/f.

32 Villar, 1982: 101-138.

33 Gómez-Guillamón, 2010: 317.
} 




Fig. 5. Jesús Nazareno procedente del retablo de la capilla del Hospital de Jesús Nazareno de Luque, hoy en la iglesia de Santo Domingo, Lucena, Córdoba. Anónimo. Primer tercio del siglo XVIII. Fotografía del autor.

servicios que estaba recibiendo de dicha institución donde se encontraba acogido ${ }^{34}$. Pese a no tener raíz alguna que le vinculara al pueblo, este vecino supo ganarse el afecto y aprecio de sus naturales y, cuando su avanzada edad le impidió trabajar, fue acogido en el establecimiento hasta su muerte. A su donación, la superiora de la comunidad rápidamente le buscó destino: al amparo de un mal entendido espíritu renovador, decidió tapiar el retablo con un tabique cubierto con láminas de madera y cegar la cúpula del presbiterio con una techumbre lisa decorada con placas y moldes de escayola sin policromar. Finalmente remató su actuación cubriendo todo el suelo de la capilla con una nueva solería de terrazo. Las hornacinas laterales y baranda del presbiterio desaparecieron, consiguiendo de este modo un perfecto rectángulo en planta. Lo que había sido durante siglos una genuina y graciosa capilla, quedaba convertida en una nave sin encanto y apta para cualquier uso ${ }^{35}$.

Finalmente, las obras de la década de 1990 volvieron a sacar a la luz el retablo y la cúpula del altar mayor. Tras muchos esfuerzos económicos y, gracias al interés personal de algunos vecinos de la localidad, se deshizo el tabique que ocultaba el retablo y se eliminó la falsa cubierta sobre la que se escondía la primitiva y original media naranja. Del mismo modo se aprovechó para cambiar nuevamente la solería, eliminando las losas de terrazo y colocando unas nuevas de mármol. Por último, se llevaron a cabo algunas obras de adecentamiento y decoración del interior de la Capilla con motivo de la fundación de la Cofradía de Nuestro Padre Jesús en su entrada triunfal en Jerusalén que, desde 1999, fijó su sede en dicha iglesia.

Es, en conclusión, la narración de una de las obras más peculiares, y quizás menos conocidas, del escultor francés Miguel Verdiguier, maestro que trabajó más de la mitad de su vida en Andalucía, especialmente en Córdoba, desde mediados del siglo XVIII, contribuyendo a la difusión de las nuevas corrientes artísticas irradiadas desde Italia, con especial fijación en el tradicional clasicismo francés de corte versallesco anterior a la Revolución. Hay que destacar que la figura de Verdiguier, a través de la bibliografía específica de la segunda mitad del setecientos, es presentada dentro del panorama artístico español

\footnotetext{
34 Estrada, 1988: 61.

35 Cabezas/Porres, 2017: 45-72.
} 
como una de las personalidades foráneas que alteraron la tradicional línea barroca seiscentista, contribuyendo a la implantación del Neoclasicismo que impuso la madrileña Real Academia de San Fernando a finales del siglo XVIII. Sin embargo este maestro marsellés, académico de espíritu y formación, con obras como el retablo de la Capilla del Hospital de Jesús Nazareno de Luque, aportó más a nuestro país por sus soluciones y conocimientos sobre el barroco italiano, que por su supuesto academicismo de origen. El ejemplo del retablo que hemos analizado sigue siendo un testimonio de época y muestra indiscutible de la estética del segundo cuarto del setecientos con la que concluyó una época: la Modernidad, definitivamente extinguida tras la Revolución francesa de 1789 que puso fin al sistema del Antiguo Régimen. 


\section{Bibliografía}

Buesa, J/Oruezabal, R. M.: Estudio grafológico de las cartas autógrafas de Verdiguier a la Academia de Marsella (1761-1777). Vitoria: Instituto de Técnicas Psicografológicas del País Vasco. (2003).

Cabezas, Á./Porres, J.: "Retablos neoclásicos sevillanos desaparecidos durante el siglo XX”. En: Revista de Humanidades, n 32, (2017), pp. 45-72.

Espinosa, G.: Arquitectura de la conversión y evangelización en la Nueva España durante el siglo XVI. Almería: Servicio de Publicaciones de la Universidad. (1999).

Estrada, V.: El Hospital de Nuestro Padre Jesús Nazareno de Luque. Córdoba: Excma. Diputación Provincial. (1988).

Feret, B.: "Los escultores marselleses y la oferta religiosa barroca". En: Revista Provenza Histórica, no 137, (1984), s/p.

Gómez, J.: Catálogo de los obispos de Córdoba, y breve noticia histórica de su iglesia catedral y obispado. Córdoba: Oficina de D. Juan Rodríguez. (1788).

Gómez-Guillamón, A.: El escultor Juan Miguel Verdiguier. Córdoba: Séneca. (2010).

Jiménez, M.: Historia de la asistencia social en España en la Edad Moderna. Madrid: Centro Superior de Investigaciones Científicas. (1958).

Nieto, M.: La catedral de Córdoba. Córdoba: Publicaciones de la Obra Social y Cultural Cajasur. (1988).

Réau, L.: Iconografía del arte cristiano. Vol. 1, tomo 1: Iconografía de la Biblia. Antiguo Testamento. Barcelona: Ediciones del Serbal. (1999).

Recio, Á.: "José Gabriel González, práctico en obras de estuco, y los retablos neoclásicos de la capilla de Maracaibo de la Catedral de Sevilla". En: Laboratorio de Arte, n 12, (1999), pp.315-322.

Sánchez-Mesa, D.: "Sobre los tres retablos de la Capilla de San Cecilio de la Catedral de Granada y el Barroco atemperado. Puntualizaciones estilísticas y documentación (1774-1787). En: Cuadernos de Arte de la Universidad de Granada, nº 23, (1992), pp.269296.

Valverde, J.: Ensayo socio-histórico de los retablistas cordobeses del siglo XVIII. Córdoba: Monte de Piedad y Caja de Ahorros. (1974).

Villar, A.: "Barroco y clasicismo en la imaginería cordobesa del Setecientos". En: Apotheca. Revista del Departamento de Historia del Arte de la Universidad de Córdoba, 1982, n 2, (1982), pp. 101-138. 